Article

\title{
Ectopic Expression of Poplar ABC Transporter PtoABCG36 Confers Cd Tolerance in Arabidopsis thaliana
}

\author{
Huihong Wang ${ }^{\dagger}$, Yuanyuan Liu ${ }^{\dagger}$, Zaihui Peng, Jianchun Li, Weipeng Huang, Yan Liu, \\ Xuening Wang, Shengli Xie, Liping Sun, Erqin Han, Nengbiao Wu, Keming Luo and \\ Bangjun Wang * \\ Chongqing Key Laboratory of Plant Resource Conservation and Germplasm Innovation, Key Laboratory of \\ Eco-Environments in Three Gorges Reservoir Region (Ministry of Education), College of Life Sciences, \\ Southwest University, Chongqing 400715, China \\ * Correspondence: bangjunwang@swu.edu.cn; Tel.: +86-23-6825-3235 \\ + These authors contributed equally to this work.
}

Received: 17 May 2019; Accepted: 1 July 2019; Published: 4 July 2019

check for updates

\begin{abstract}
Cadmium (Cd) is one of the most toxic heavy metals for plant growth in soil. ATP-binding cassette $(\mathrm{ABC})$ transporters play important roles in biotic and abiotic stresses. However, few $A B C$ transporters have been characterized in poplar. In this study, we isolated an $\mathrm{ABC}$ transporter gene PtoABCG36 from Populus tomentosa. The PtoABCG36 transcript can be detected in leaves, stems and roots, and the expression in the root was 3.8 and 2 times that in stems and leaves, respectively. The PtoABCG36 expression was induced and peaked at $12 \mathrm{~h}$ after exposure to $\mathrm{Cd}$ stress. Transient expression of PtoABCG36 in tobacco showed that PtoABCG36 is localized at the plasma membrane. When overexpressed in yeast and Arabidopsis, PtoABCG36 could decrease Cd accumulation and confer higher $\mathrm{Cd}$ tolerance in transgenic lines than in wild-type (WT) lines. Net $\mathrm{Cd}^{2+}$ efflux measurements showed a decreasing Cd uptake in transgenic Arabidopsis roots than WT. These results demonstrated that PtoABCG36 functions as a cadmium extrusion pump participating in enhancing tolerance to $\mathrm{Cd}$ through decreasing $\mathrm{Cd}$ content in plants, which provides a promising way for making heavy metal tolerant poplar by manipulating ABC transporters in cadmium polluted areas.
\end{abstract}

Keywords: Cd; PtoABCG36; tolerance; poplar; accumulation; efflux

\section{Introduction}

Cadmium $(\mathrm{Cd})$ is a highly toxic pollutant in the environment. Cadmium is nephrotoxic, and it can lead to serious human diseases, including kidney disorders, bone damage and neurotoxicity [1]. For example, high environmental exposure in Japan resulting from a stable diet of cadmium contaminated rice caused itai-itai disease [2]. Cadmium can inactivate or denature proteins by binding to the sulfhydryl groups, leading to cellular damage by displacing co-factors from a variety of proteins including transcription factors and enzymes, and by indirectly generating reactive oxygen species [3,4]. Heavy metal pollution in agricultural soils has become a serious problem. Therefore, it is essential to prevent cadmium from getting into the food chain and make the best use of cadmium contaminated soil.

Plants are able to tolerate heavy metal stress to a certain extent, with the participation of some transporters. These transporters can enhance heavy metal tolerance by pumping heavy metals into vacuoles or out of cells. Previous studies showed that two type 1(B) heavy metal-transporting subfamily of the P-type ATPases AtHMA2 and AtHMA4 are localized at the plasma membrane and 
can transport excessive zinc and cadmium to the outside of the cell in Arabidopsis thaliana, which are important players in the plant detoxification process [5]. The members of the cation diffusion facilitator (CDF) family, natural resistance-associated macrophage protein (Nramp) and Zrt/IRT-like protein (ZIP) families of transporters are also involved in the transport of heavy metals in a variety of organisms [6,7]. In addition, ATP-binding cassette (ABC) transporters are essential for plant growth and development. ABC transporters are driven by ATP hydrolysis and can act as exporters as well as importers. The Arabidopsis nuclear genome encodes for more than $100 \mathrm{ABC}$ transporters, which are divided into eight subfamilies (ABCA, $A B C B, A B C C, A B C D, A B C E, A B C F, A B C G$ and $A B C I)$, largely exceeding that of animal. Most plant $A B C$ transporters are present in cell membranes and are involved in detoxification processes, organ growth, plant nutrition, plant development and response to abiotic and biotic stresses [8]. Some ABC transporters are closely related to the detoxification of heavy metals. In Saccharomyces cerevisiae, an ABCC-like heavy metal transporter ScYCF1 (yeast cadmium factor 1 ) has been found to contribute to detoxifying cadmium by pumping it into vacuoles [9], and overexpression of ScYCF1 in Arabidopsis can improve cadmium tolerance [10]. Similarly, a half-size ABC transporter HMT1 (heavy metal tolerance 1) from Schizosaccharomyces pombe can transport phytochelatin-Cd complexes into the vacuole, which is considered to be the first transporter to transport heavy metal-phytochelatin complexes [11]. AtABCB25/AtATM3, a close homolog of SpHMT1, contributes to Cd resistance and can transport glutamine synthetase conjugated Cd (II) across the mitochondrial membrane [12]. Full-size ABC transporters AtABCC1 and AtABCC2 have been demonstrated to be major vacuolar phytochelatins (PCs) transporters to participate in arsenic (As), mercury $(\mathrm{Hg})$ and $\mathrm{Cd}$ resistance in Arabidopsis [13], and their homologous rice $\mathrm{ABCC}$ transporter OsABCC1 is involved in the As detoxification and reduces As accumulation in the rice grains [14]. Another homologous ABCC transporter PtABCC1 can enhance tolerance to $\mathrm{Cd}$ in poplar [15]. It has reported that AtABCC3 can complement the Cd sensitive phenotype of the ycf1 mutant in Saccharomyces cerevisiae [16]. The level of expression of AtABCC6/AtMRP6 can be up-regulated in response to cadmium (Cd) treatment [17]. Furthermore, some ABCG subfamily transporters are also involved in heavy metal resistance. AtABCG36/PDR8, localized at the plasma membrane, plays an important role in Cd extrusion from root cells [18]. The transcription of cucumber genes CsPDR8/CsABCG36 can be up-regulated under Cd stress [19]. The rice OsABCG43/PDR5 is a Cd inducible-transporter and confers high Cd resistance in yeast cells [20].

Poplar is a woody plant with established genetic transformation system and abundant biomass. In China, there is a very large number of Populus tomentosa, taking up very large land resources. The previous research on poplar mainly focuses on insect resistance, herbicide resistance, biomass traits, stress tolerance, disease resistance, hormone modification, flowering modification and phytoremediation [21]. Recently, a study found that exogenous abscisic acid (ABA) stimulated the expression level of poplar ABCG40 transporter involved in lead (Pb) uptake, transport and detoxification [22]. The two multidrug and toxic compound extrusion (MATE) family genes PtrMATE1 and PtrMATE2 from poplar induced by aluminum (Al) can enhance aluminum resistance in acidic soils [23]. The YCF1-expressing transgenic poplar plants exhibited enhanced growth, reduced toxicity symptoms, and increased $\mathrm{Cd}$ content in the aerial tissue compared to the non-transgenic plants [24]. However, there are few studies on poplar ABCG transporters involved in Cd resistance. Therefore, the engineering of Populus tomentosa by manipulating $\mathrm{ABC}$ transporters is a significant step towards the effective utilization of $\mathrm{Cd}$ contaminated soil.

In the present study, we cloned a novel ABC transporter gene PtoABCG36 (GenBank accession: MH660448) by BLAST search in the poplar database using AtABCG36 as a query sequence. Yeast and Arabidopsis overexpressing PtoABCG36 were measured in terms of their $\mathrm{Cd}$ tolerance and $\mathrm{Cd}$ content after $\mathrm{Cd}$ treatment. The results showed that overexpressing PtoABCG36 is effective in enhancing $\mathrm{Cd}$ tolerance through decreasing $\mathrm{Cd}$ content in plants, indicating that PtoABCG36 transporter functions as a cadmium extrusion pump to participate in Cd stress in plants, which provides a reasonable way to make heavy metal tolerant poplar by manipulating $\mathrm{ABC}$ transporters in the areas with cadmium pollution. 


\section{Results}

\subsection{Structural and Phylogenetic Analysis of PtoABCG36}

PtoABCG36 was isolated from full-length cDNA of leaves of six-month-old Populus tomentosa and submitted to GenBank (accession number: MH660448). The sequence encoded 1478 amino acid residues and contained two putative transmembrane domains (TMD) and two putative nucleotide-binding domains (NBD) (Figure 1A). Each NBD domain has about 200 amino acid residues, and it contains a Walker A motif (GXXGXGKS/T), a Walker B motif (hhhhD) and an ABC signature motif (LSGGQQ/R/KQR) [25]. Some ABCG subfamily transporters have been identified in many plant species, including Arabidopsis thaliana, Glycine Max, Ricinus conmunis, Vitis vinifera, Gossypium arboretum and Oryza sativa. The two NBD domains are highly conserved (Figure 1A).

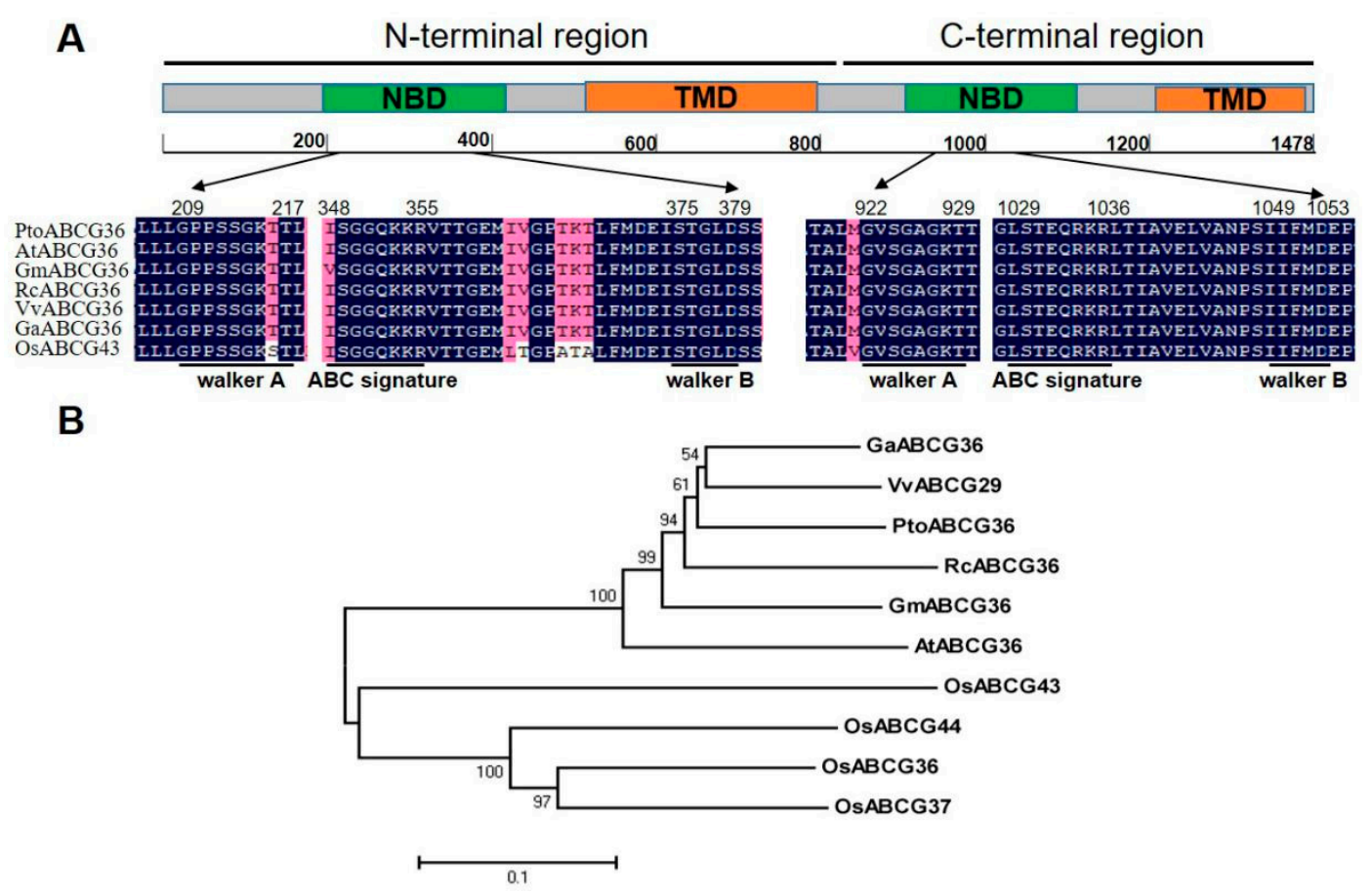

Figure 1. Amino acid sequence alignment and phylogenetic analysis. (A) Structure analysis and amino acid multi-alignment of the nucleotide-binding domains (NBD) of ABCG proteins from different plant species. ABCG domains are marked as two green and orange blocks. TMD, transmembrane domain; Walker A, ATP-binding cassette (ABC) signature; Walker B, NBD associated motifs. Blue indicates identical amino acids; pink indicates similar amino acids. (B) Phylogenetic analysis of ABCG proteins from Populus trichocarpa (PtoABCG36, MH660448); Arabidopsis thaliana (AtABCG36, NP_176196); Oryza sativa (OsABCG36, XP_015648358; OsABCG37, XP_015648329; OsABCG43, XP_015646575; OsABCG44, XP_015650488); Glycine Max (GmABCG36, XP_006585572); Ricinus conmunis (RcABCG36, XP_002515970); and Vitis vinifera (VvABCG29, XP_010654625); Gossypium arboretum (GaABCG36, $\left.X P \_017606959\right)$. The numbers beside the branches represent bootstrap values based on 1000 replications.

To investigate the homology between PtoABCG36 and other plant species, ten plant ABCG transporters were analyzed. PtoABCG36 had $81.9 \%, 81.4 \%, 78.4 \%, 78.2 \%$ and $74.1 \%$ amino acid sequence similarity to GaABCG36 (XP_017606959), VvABCG29 (XP_010654625), GmABCG36 (XP_006585572), RcABCG36 (XP_002515970) and AtABCG36 (NP_176196), respectively. Phylogenetic analysis also revealed that PtoABCG36 was homologous with the ABCG proteins from dicotyledons such as Vitis vinifera, Gossypium arboretum, Ricinus conmunis, Glycine Max and Arabidopsis thaliana, as well as monocotyledons such as Oryza sativa (Figure 1B).

\subsection{The PtoABCG36 Gene Is Highly Expressed in Response to Cd Stress in Poplar}


To confirm the function of the PtoABCG36 transporter, we measured its gene expression level. PtoABCG36 transcript can be detected in leaves, stems and roots, and the expression in the root was 3.8 and 2 times that of the stems and leaves, respectively. The higher expression level in the roots indicated that PtoABCG36 mainly functioned in the roots (Figure 2A). In addition, to confirm the function of PtoABCG36 in response to $\mathrm{Cd}$ stress, we performed induced expression using quantitative real-time PCR after the six-month-old poplars were immersed in woody plant medium (WPM) supplemented with different concentrations of $\mathrm{CdCl}_{2}$ for $12 \mathrm{~h}$. Poplar gene-specific primers were used for qRT-PCR analysis of PtoABCG36. The results showed that the expression of PtoABCG36 was significantly increased in roots with increasing cadmium concentration and reached the highest level when treated with $100 \mu \mathrm{M} \mathrm{CdCl}_{2}$ for $12 \mathrm{~h}$. PtoABCG36 expression was also significantly increased in stems and leaves but not as highly as that in roots. However, when treated with 150 or $200 \mu \mathrm{M} \mathrm{CdCl}_{2}$, the expression of the PtoABCG36 gradually declined, but it could still be induced in roots, stems and leaves (Figure 2B). Furthermore, temporal spatial expression analysis upon treatment with $100 \mu \mathrm{M} \mathrm{CdCl}_{2}$ for $24 \mathrm{~h}$ showed that PtoABCG36 transcript increased overtime and peaked at $12 \mathrm{~h}$, with a level seven times that of the control, then gradually decreased (Figure 2C). These results further determined that PtoABCG36 could be induced and participate in resisting $\mathrm{Cd}$ stress.
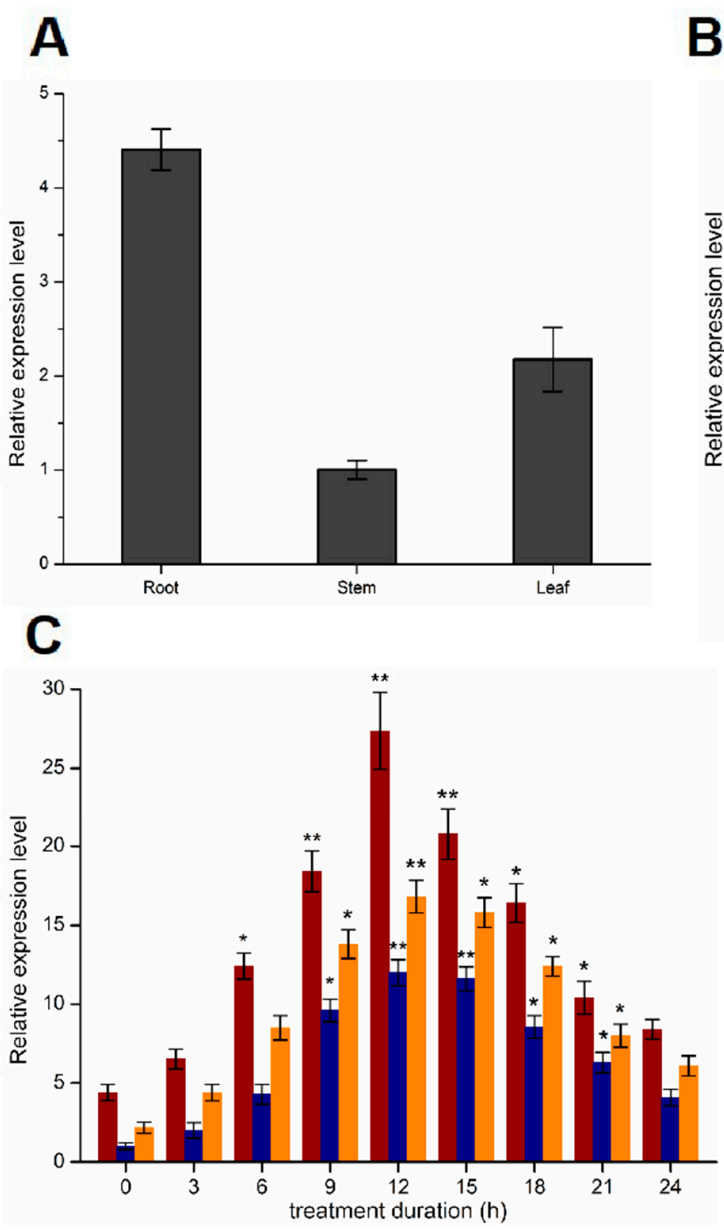

B

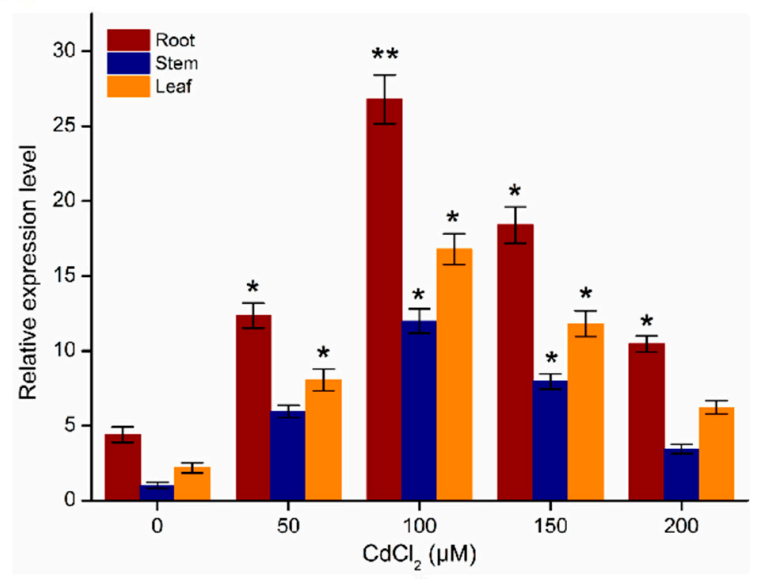

Figure 2. Expression analysis of PtoABCG36 gene. (A) Relative expression level of PtoABCG36 gene in roots, stems, leaves of Populus tomentosa. (B) Expression of PtoABCG36 in poplar roots, stems and leaves under different concentrations of $\mathrm{Cd}^{2+}$ for12 $\mathrm{h}$. (C) Time course of PtoABCG36 expression in poplar roots, stems and leaves in response to $100 \mu \mathrm{M} \mathrm{Cd}^{2+}$ treatment. The results are shown as the mean expression \pm standard deviation (SD) of three independent experiments. Poplar ubiquitin $(U B Q)$ expression was used as a control and gene-specific primers were used for qRT-PCR analysis of PtoABCG36 gene. Student's t-test, ${ }^{*} p<0.05,{ }^{* *} p<0.01$. 


\subsection{The PtoABCG36 Transporter is Localized at the Plasma Membrane}

In order to determine the subcellular localization of PtoABCG36, the 35S:PtoABCG36-GFP construct, in which the PtoABCG36-GFP fusion gene was driven by the CaMV 35S promoter, was transiently expressed in the leaves of three-week-old Nicotiana benthamiana. Compared with the control where GFP was observed at the plasma membrane (PM), endoplasmic reticulum (ER) and nucleus (NU) in the epidermal cells (Figure 3A-D), the PtoABCG36 signal was observed only at the plasma membrane (Figure 3E-H), indicating that PtoABCG36 is localized at the plasma membrane to function as transporter, consistent with the localization pattern of AtABCG36 in Arabidopsis thaliana.
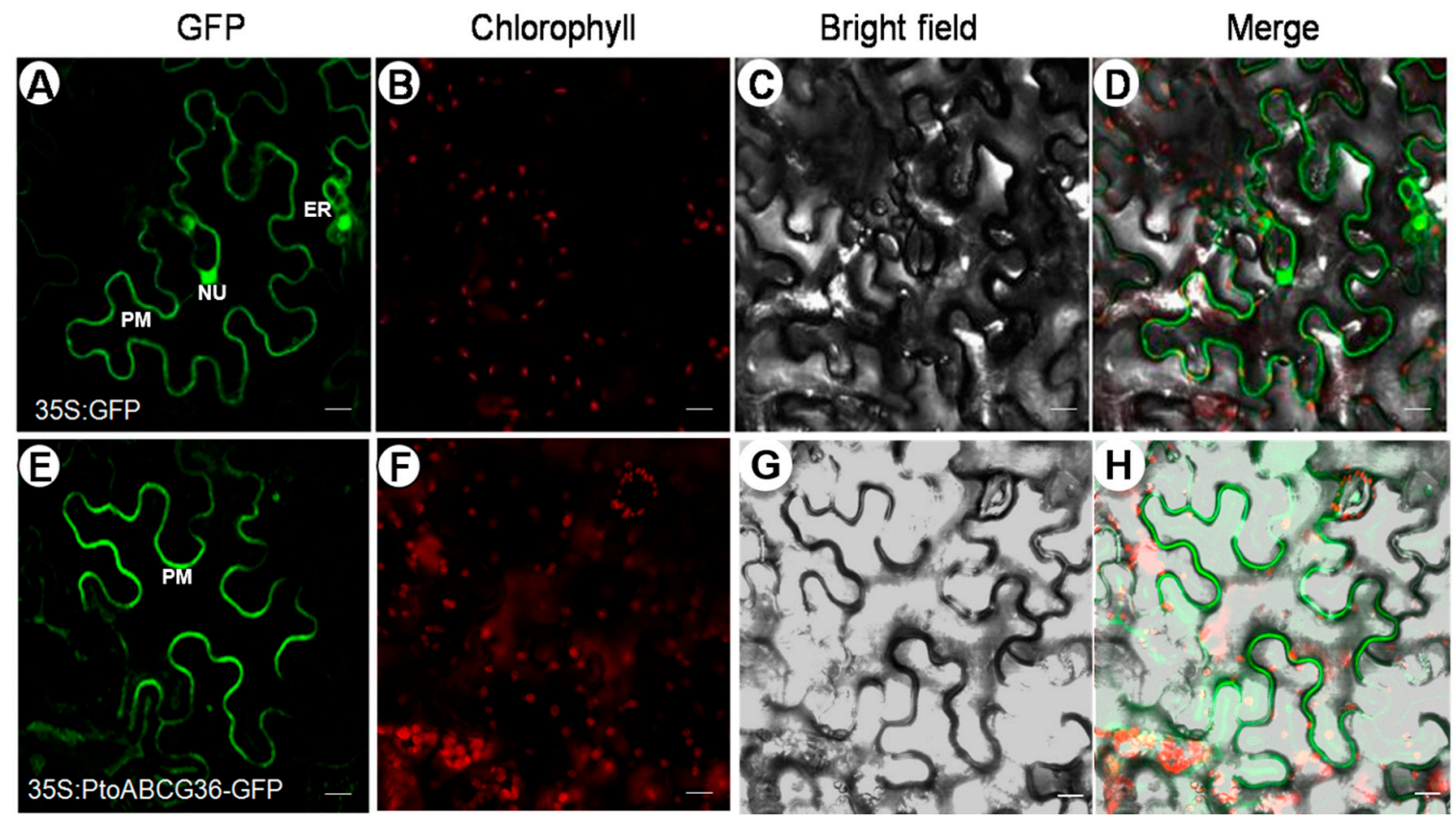

Figure 3. Subcellular localization of PtoABCG36 in epidermal cells of Nicotiana benthamiana. The fluorescence of green fluorescent protein (GFP) or PtoABCG36-GFP signal in tobacco leaf cell (A,E). Chlorophyll autofluorescence (B,F). Bright field (C,G). The overlap images of bright field and fluorescence images $(\mathbf{D}, \mathbf{H})$. Scale bars $=20 \mu \mathrm{m}$. NU, nucleus; PM, plasma membrane; ER, endoplasmic reticulum.

\subsection{Heterologous Expression of PtoABCG36 Confers Cd Tolerance in Yeast}

To investigate whether PtoABCG36 is involved in Cd tolerance, pDR-PtoABCG36 was produced and transformed into the yeast $\mathrm{Cd}$ sensitive mutant strain $\triangle y a p 1$ and wild-type strain $\mathrm{Y} 252$. We found that on the SD-Ura medium, growth was similar between the yeast cells carrying the empty vector and those expressing PtoABCG36. However, on the SD-Ura medium containing $100 \mu \mathrm{M}$ or $200 \mu \mathrm{M}$ $\mathrm{CdCl}_{2}$, the $\triangle y a p 1$ or $\mathrm{Y} 252$ with pDR-PtoABCG36 exhibited stronger $\mathrm{Cd}$ tolerance than mutants or wild-type with the empty vector (Figure 4A). Yeast growth in liquid SD-Ura medium containing $40 \mu \mathrm{M}$ $\mathrm{CdCl}_{2}$ was analyzed overtime. In the absence of $\mathrm{Cd}$, there was no growth difference between the PtoABCG36-carrying yeast and the control (Figure 4B). However, upon $\mathrm{CdCl}_{2}$ exposure, the growth of PtoABCG36-carrying $\triangle y a p 1$ and Y252 were better than the yeast cells carrying the empty vector. Additionally, complementary strains partially restored their tolerance to Cd (Figure 4C), further confirming heterologous expression of PtoABCG36 could confer Cd tolerance in yeast. 

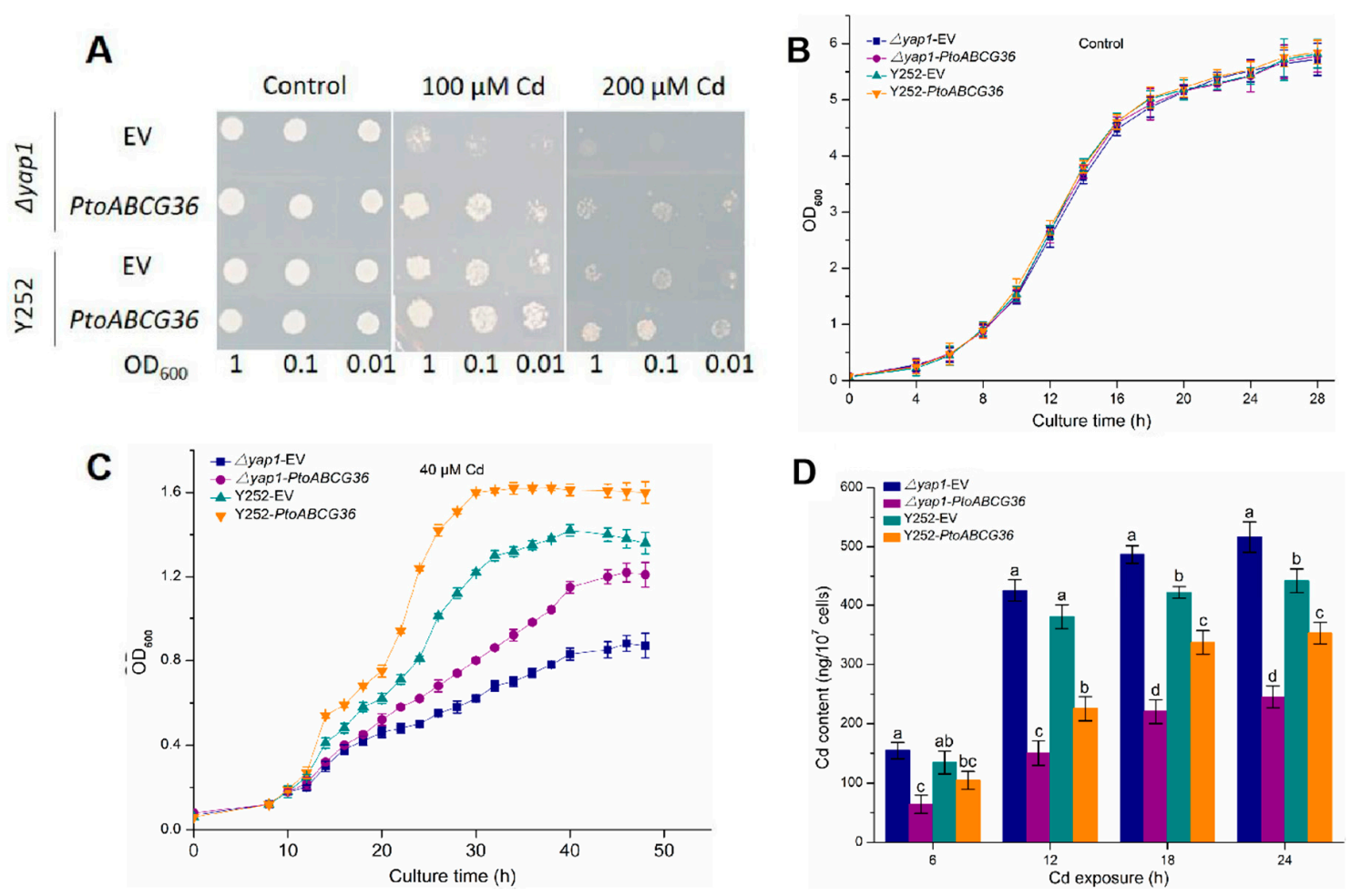

Figure 4. PtoABCG36 enhances cadmium tolerance in yeasts. (A) $\triangle$ yap1 and the wild-type Y252 were transformed with EV (pDR196 empty vector) and pDR196-PtoABCG36, and grown on SD plates with indicated concentrations of $\mathrm{CdCl}_{2}$ for $7 \mathrm{~d}$. (B,C) Growth curves of yeast cells $\Delta$ yap1-EV (square), $\Delta$ yap1PtoABCG36 (circle), Y252- EV (up-triangle) and Y252- PtoABCG36 (down-triangle) under control (B) and $40 \mu \mathrm{M} \mathrm{CdCl}_{2}$ condition (C) for indicated time. (D) Accumulation of cadmium in $\triangle y a p 1-\mathrm{EV}$ (navy blue), $\triangle$ yap1-PtoABCG36 (purple), Y252-EV (dark cyan) and Y252-PtoABCG36 (orange) yeasts. Yeast cells $\left(1 \times 10^{7}\right)$ were exposed to $40 \mu \mathrm{M} \mathrm{Cd}$ treatment for $6,12,18$ or $24 \mathrm{~h}$ at $30^{\circ} \mathrm{C}$. Cd concentrations in the yeast cells were measured by ICP-OES. Error bars indicate standard deviation $(n=3)$. Different letters indicated significant differences $(p<0.05)$.

Previous studies have shown that yeast could resist cadmium by transporting it into the vacuoles or out of the cells. We tested Cd concentration in the yeast cells culturing in liquid SD-Ura medium containing $40 \mu \mathrm{M} \mathrm{CdCl}_{2}$. As shown in Figure $4 \mathrm{D}$, after $24 \mathrm{~h}$ of treatment, the accumulation of $\mathrm{Cd}$ in PtoABCG36-carrying $\triangle$ yap 1 and Y252 was significantly less (52.5\% and $20.3 \%$ less, respectively) than that in mutant and wild-type. These results indicated that PtoABCG36 can contribute to Cd resistance by transporting it out of the yeast cells.

\subsection{Overexpression of PtoABCG36 Increases Tolerance to $C d$ and Decreases $C d$ Accumulation in Plants}

In order to investigate the function of PtoABCG36 in plants, the construct 35S:PtoABCG36 was introduced into Arabidopsis. The PtoABCG36 transcript levels were detected by qRT-PCR for further analysis (Supplementary Figure S2). Arabidopsis transgenic plants T4, wild-type and mutant seeds were analyzed after treatment without $\mathrm{Cd}$ and with $20 \mu \mathrm{M}, 40 \mu \mathrm{M}$ or $60 \mu \mathrm{M} \mathrm{CdCl}_{2}$ for 2 weeks. There was no growth difference among these lines in the absence of $\mathrm{Cd}$, while the growth of Arabidopsis was significantly inhibited when grown on half MS agar plates containing $20 \mu \mathrm{M}, 40 \mu \mathrm{M}$ and $60 \mu \mathrm{M}$ $\mathrm{CdCl}_{2}$. The $a b c g 36$ mutants displayed shortest roots. However, the transgenic plants had longer roots and grew better than wild-type plants (Figure 5A,B), indicating that PtoABCG36 was also involved in mediating tolerance to $\mathrm{Cd}$ in plants. Quantitative analysis showed that the roots of overexpression lines (OX-2 and OX-3) were significantly longer than those of wild-type plants in the presence of $40 \mu \mathrm{M}$ $\mathrm{CdCl}_{2}$ (44\% and $48 \%$ longer, respectively) and $60 \mu \mathrm{M} \mathrm{CdCl}_{2}(116.7 \%$ and $112.5 \%$ longer, respectively). These results further indicated that PtoABCG36 enhanced tolerance to Cd in plants. 

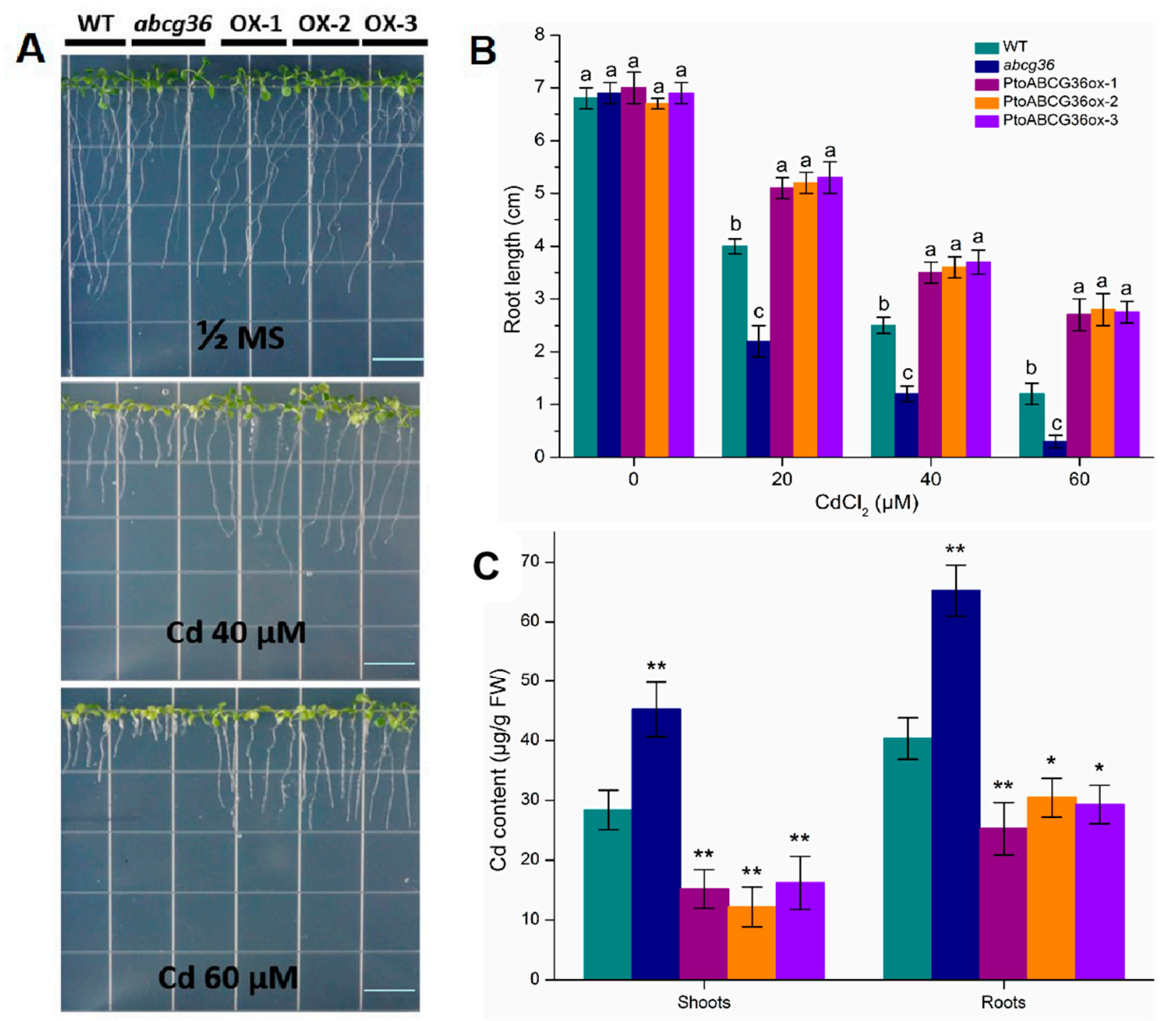

Figure 5. PtoABCG36 enhances cadmium tolerance in Arabidopsis. Arabidopsis seeds were grown on half-strength MS medium containing 0, 40 or $60 \mu \mathrm{M} \mathrm{CdCl}_{2}$ for two weeks (A) and primary root length (B) were analyzed. (C) Accumulation of cadmium in plants after treatment with the half MS liquid medium containing $100 \mu \mathrm{M} \mathrm{CdCl}_{2}$ for $24 \mathrm{~h}$. For root lengths, $n=120-124$ from three independent experiments. WT, wild-type; $a b c g 36$, abcg36 mutant SALK_1422526; OX-1 and OX-2, OX-3 PtoABCG36-overexpressing Arabidopsis lines. White bars $=15 \mathrm{~mm}$. Cd concentrations in plants were measured by ICP-OES. Error bars indicate standard deviation. Different letters indicated significant differences $(p<0.05)$. Student's t-test, ${ }^{*} p<0.05,{ }^{* *} p<0.01$.

To explain the detoxification mechanism of PtoABCG36 in plants, we tested the cadmium content in the mutants, wild-type and transgenic plants after treatment with the half MS liquid medium containing $100 \mu \mathrm{M} \mathrm{CdCl}_{2}$ for $24 \mathrm{~h}$. We found that transgenic plants OX-1, OX-2 and XO-3 had lower Cd content than wild-type in the shoots $(46.68 \%, 57 \%$ and $42.91 \%$ lower, respectively) and roots (37.42\%, $22.3 \%$ and $27.37 \%$ lower, respectively). In contrast, the mutant $a b c g 36$ had higher Cd content than the wild-type in the roots (61.65\% higher) and shoots (59.24\% higher). More importantly, the levels of cadmium reduction in the roots of transgenic plants were much greater than those in the shoots (Figure 5C), suggesting that PtoABCG36 contributed to Cd tolerance by pumping it out of the plants and reducing $\mathrm{Cd}$ toxicity in plant roots.

To further determine the function of PtoABCG36 in plant roots, we investigated the $\mathrm{Cd}^{2+}$ uptake in root tips of abcg36 mutants, WT and plants overexpressing PtoABCG36 through a non-invasive micro-test (NMT) technique. In the presence of $50 \mu \mathrm{M} \mathrm{CdCl}_{2}$, the net $\mathrm{Cd}^{2+}$ influxes of OX-1, OX-2 and OX-3 lines were lower than WT plants (62.39\%, 54.50\% and 53.30\% lower, respectively) (Figure 6). In contrast, the mutant $a b c g 36$ had higher $\mathrm{Cd}$ net $\mathrm{Cd}^{2+}$ influx than the WT plants. These results 
indicated that a decreasing $\mathrm{Cd}$ uptake capacity existed in lines overexpressing PtoABCG36 than the WT plants.

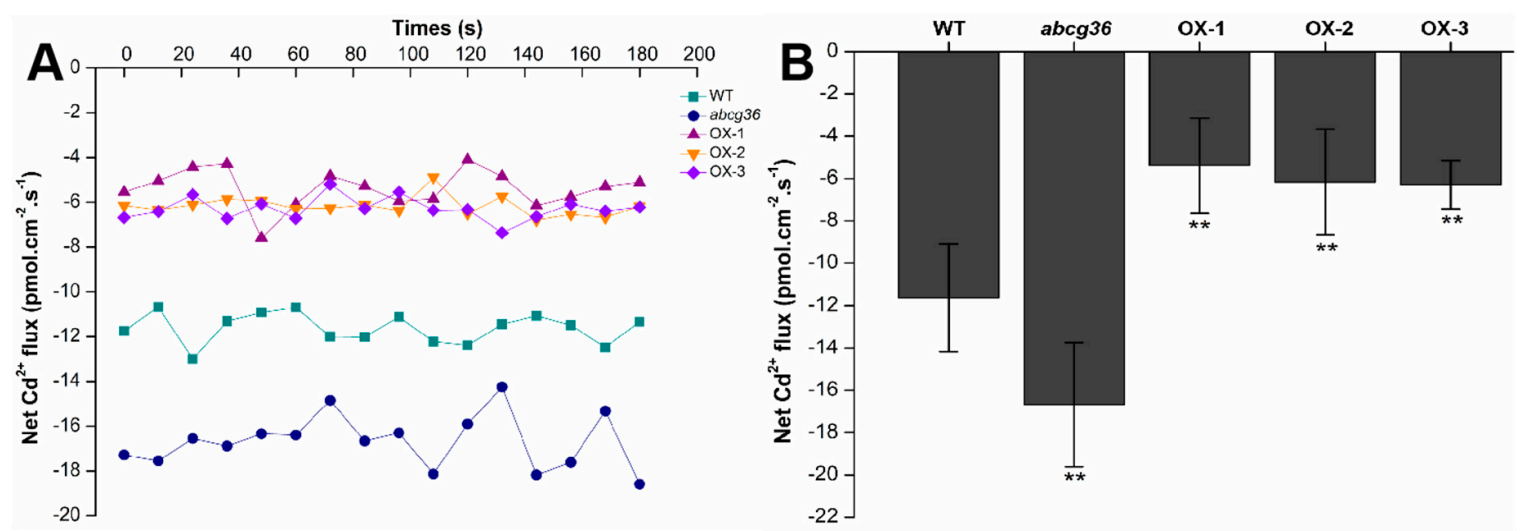

Figure 6. Net $\mathrm{Cd}^{2+}$ fluxes. Net $\mathrm{Cd}^{2+}$ fluxes in the roots of $\mathrm{WT}$, abcg36 mutant and transgenic plants (OX-1, OX-2, and OX-3) treated with $\mathrm{CdCl}_{2}$ stress (A). The average $180 \mathrm{~s} \mathrm{net} \mathrm{Cd}^{2+}$ fluxes are illustrated to highlight the trend differences (B). Bars indicate means \pm SD. Student's t-test, ${ }^{*} p<0.05,{ }^{* *} p<0.01$.

\section{Discussion}

To date, how to effectively use soil containing cadmium has become a worldwide problem. Previous studies have showed that several transporters, including the P-type ATPases AtHMA2 and AtHMA4, the CDF, Nramp and ZIP families of transporters and ABC transporters could be involved in the heavy metal tolerance [5-7,9-11].

In this study, we identified the $\mathrm{ABC}$ transporter ABCG36 of Populus tomentosa. Protein sequence analysis showed that it contained conserved Walker A, Walker B, and $A B C$ signal (Figure $1 \mathrm{~A}$ ). In previous studies, Walker $\mathrm{A}$, Walker $\mathrm{B}, \mathrm{ABC}$ signal of NBD were demonstrated to function as $\mathrm{ABC}$ transporters motifs [26]. Phylogenetic tree analysis showed that PtoABCG36 in poplar is an ortholog of Arabidopsis AtABCG36, which acts as transporter involved in biotic or abiotic stress [18,27] (Figure 1B). Expression pattern showed that the accumulation of PtoABCG36 transcript was mainly detected in the roots (Figure 2A). In line with our results (Figure 2B,C), it has been also reported that transcript levels of ABCG transporters were induced rapidly by biotic or abiotic stress [28-32]. Interestingly, PtoABCG36 expression was induced by $\mathrm{Cd}$, peaking at $12 \mathrm{~h}$ after $\mathrm{Cd}$ treatment. Additionally, the expression of PtoABCG36 was significantly higher in poplar roots than that in shoots under Cd treatment, which is different from its ortholog in other species (Figure 2C).

It is important for plants to cope with heavy metal stress. In this study, first, we found that ectopic expression of PtoABCG36 in yeast and Arabidopsis all significantly increased Cd tolerance (Figures 3 and 5). Interestingly, our data showed that the growth of PtoABCG36-carrying $\triangle$ yap 1 yeast stain, which has a lower level of Cd, was not better than that of the wild-type Y252 (Figure 4C,D). It is known that Yap1 increased cellular tolerance to cadmium by activating the expression of ScYCF1 as a transcription factor. Yeast wild-type $\mathrm{Y} 252$ can resist $\mathrm{Cd}$ stress through $\mathrm{ABC}$ transporter ScYCF1 localized at vacuolar membrane and plasma membrane pumping $\mathrm{Cd}$ into vacuoles or out from the cells [10]. The expression of YCF1 in Y252-PtoABCG36 could pump Cd into vacuoles, while inhibition of YCF1 in $\triangle$ yap1-PtoABCG36 could decrease the transport of heavy metals to vacuoles. Therefore, Y252-PtoABCG36 has higher accumulation of Cd compared to $\triangle$ yap1-PtoABCG36 (Figure 4D). In addition, our data indicated that Arabidopsis Pto $A B C G 36$-overexpressing lines could enhance $C d$ tolerance (Figure 5). The abcg36 plants are sensitive to $\mathrm{Cd}$, whereas the PtoABCG36-overexpressing plants are tolerant (Figure 5). PtoABCG36-overexpressing plants have reduced cadmium content in their shoots and roots, but $a b c g 36$ plants were the opposite. The wild-type plants accumulate 1.2 to 1.5 times as much $\mathrm{Cd}$ in roots and shoots as the transgenic plants (Figure 5C), suggesting that the overexpression of PtoABCG36 could expel heavy metals from plants. Non-invasive micro-test (NMT) 
technique showed that overexpressing PtoABCG36 can decrease Cd uptake capacity in plants (Figure 6). The detoxification mechanism of PtoABCG36 might be similar to that of its homologous AtABCG36 located at the plasma membrane, which can transport Cd out from the cells.

Taken together, our study provided the evidence for the biological functions of PtoABCG36 as a transporter in regulating Cd resistance in plants. Additionally, it plays a crucial role in reducing $\mathrm{Cd}$ accumulation in plants, providing a theoretical basis to make heavy metal tolerant poplar by manipulating $\mathrm{ABC}$ transporters in cadmium polluted areas. The present study has also provided insight on the roles of ABCG transporters in economic forest cultivation.

\section{Materials and Methods}

\subsection{Materials and Growth Conditions}

Arabidopsis seeds of wild-type (ecotype Columbia-0), abcg36 (a loss-of-function mutant of AtABCG36, SALK_1422526) [18], and transgenic plants OX-1, OX-2, OX-3 were vernalized in the dark at $4{ }^{\circ} \mathrm{C}$ for 2 days, and then grew on half-strength MS agar medium plates containing $1.5 \%$ sucrose in a controlled environment with a $16 \mathrm{~h}$ light with $120 \mu \mathrm{mol} \mathrm{m}^{-2} \mathrm{~s}^{-1}$ light intensity and $8 \mathrm{~h}$ dark at $22{ }^{\circ} \mathrm{C} / 18{ }^{\circ} \mathrm{C}$ for the indicated duration.

P. tomentosa Carr. (clone 741) (Chinese white poplar), kindly provided by Institute of Resources Botany, Southwest University, and transgenic poplars were cultivated in a greenhouse at $24{ }^{\circ} \mathrm{C}$ under a $14 \mathrm{~h} / 10 \mathrm{~h}$ light/dark cycle with $45 \mu \mathrm{mol} \mathrm{m} \mathrm{m}^{-2} \mathrm{~s}^{-1}$ of light and maintained in sterile woody plant medium (WPM) containing $0.8 \%(\mathrm{w} / \mathrm{v})$ agar. Gene expression patterns were analyzed in leaves, roots and stems from 6-month-old plants.

\subsection{Gene Cloning, Expression Vector Construction, Structural and Phylogenetic Analysis of PtoABCG36}

Total RNA was extracted from the leaves of 6-month-old P. tomentosa Carr. by using the Trizol Reagent (Tiangen, China), then revers transcribed to cDNA by using the RT-AMV transcriptase Kit (TaKaRa, Dalian, China). The PtoABCG36 specific fragment was amplified by PCR using specific primers (Supplementary Table S1). Cycling conditions were: $98^{\circ} \mathrm{C}$ for $3 \mathrm{~min}$ followed by 34 cycles of $98^{\circ} \mathrm{C}$ for $30 \mathrm{~s}, 56.6{ }^{\circ} \mathrm{C}$ for $30 \mathrm{~s}$ and $72{ }^{\circ} \mathrm{C}$ for $2 \mathrm{~min} 58 \mathrm{~s}$, adding a final prolongation step at $72{ }^{\circ} \mathrm{C}$ for $10 \mathrm{~min}$. The amplification products were cloned into the BamHI site of the plant binary vector pCAMBIA-1300-GFP [33] as well as the SpeI and XmaI sites of the yeast vector pDR196 [34], to construct pCAMBIA-1300-PtoABCG36 and pDR196-PtoABCG36.

Prediction and analysis of the structure of PtoABCG36 protein was performed with the Simple Modular Architecture Research Tool (SMART, http://smart.embl-heidelberg.de). The homologous amino acid sequences of PtoABCG36 in other species were downloaded from NCBI (http://www.ncbi. nlm.nih.gov), and aligned with DNAMAN 8.0 (Lynnon Biosoft, San Ramon, CA, USA). The phylogenetic analysis of amino acid sequences was carried out with MEGA 5.0 software by using neighbor-joining (NJ).

\subsection{Transformation and Selection for Yeast and Arabidopsis}

The yeast expression vectors pDR196 and pDR196-PtoABCG36 were transformed into the Cd sensitive-yeast mutant $\triangle$ yap1 (MATa ura3 lys2 ade2 trp1 leu2 yap1::leu2) and the wild-type Y252 (MATa ura3 lys2 ade2 trp1 leu2) [35], kindly provided by Ji-Ming Gong (Shanghai Institutes for Biological Sciences, Chinese Academy of Sciences, shanghai, China) for metal sensitivity assay, as described [36]. Yap1 is a transcription factor that increases the tolerance of cells to cadmium by activating YCF1 expression [37].

pCAMBIA-1300-PtoABCG36 was transformed into the Agrobacterium tumefaciens strain GV3101, then transformed into wild-type Arabidopsis by the floral dip method [38]. The selection of putative transgenic plants was performed on half MS medium with $40 \mathrm{mg} / \mathrm{L}$ hygromycin and $200 \mathrm{mg} / \mathrm{L}$ 
cefotaxime, and further confirmed by PCR analysis (Supplementary Figure S1) and qRT-PCR analysis (Supplementary Figure S2).

\subsection{The Metal Assay of Yeast Cells and Plants}

For phenotypic analysis, yeast cells were cultured in SD-Ura liquid medium to log phase and diluted to the corresponding concentration after collection, then spotted onto SD-Ura plates containing $100 \mu \mathrm{M}$ and $200 \mu \mathrm{M} \mathrm{CdCl}_{2}$. Plates were kept at $30^{\circ} \mathrm{C}$ for 7 days before being photographed. Yeast cells were also cultured in liquid medium containing $40 \mu \mathrm{M} \mathrm{CdCl}_{2}$ for $12 \mathrm{~h}$ and $\mathrm{OD}_{600}$ was measured at indicated time [35].

For phenotypic analysis, Arabidopsis transgenic plants T4, wild-type and mutant seeds were grown on half MS agar plates in the absence or presence of 20,40 and $60 \mu \mathrm{M} \mathrm{CdCl}_{2}$ for 2 weeks before being photographed and the averages of root lengths were measured in different experiments. Four untreated seedlings, each with a distinctive genotype, were grown in the half MS liquid medium with $100 \mu \mathrm{M} \mathrm{CdCl}_{2}$ for $24 \mathrm{~h}$, and were used for determination of cadmium content. Three technical replicates were performed.

For induced expression experiment, 6-month-old poplars were immersed in WPM medium supplemented with different concentrations of $\mathrm{CdCl}_{2}$ for $12 \mathrm{~h}$. Meanwhile, poplars treated with WPM medium without $\mathrm{Cd}$ were used as control. For the temporal spatial expression analysis, 6-month-old poplars were immersed in WPM medium supplemented with $100 \mu \mathrm{M} \mathrm{CdCl}_{2}$. Roots, stems and leaves were collected every $3 \mathrm{~h}$ for real-time quantitative PCR. Three technical replicates were performed.

\subsection{Subcellular Localization of PtoABCG36}

PtoABCG36 was ligated into pCAMBIA1300-GFP vector to produce 35S:PtoABCG36-GFP, which was transiently expressed in the leaves of 3-week-old Nicotiana benthamiana to examine the subcellular localization of PtoABCG36 after $72 \mathrm{~h}$ of infiltration. The 35S:PtoABCG36-GFP construct was transformed into GV3101 cells. The cells were grown at $28^{\circ} \mathrm{C}$ to $\mathrm{OD}_{600}$ of 0.8 , resuspended in infiltration buffer (10 mM MES, $\mathrm{pH}=5.7,10 \mathrm{mM} \mathrm{MgCl} 2$, and $100 \mu \mathrm{M}$ acetosyringone) to adjust the $\mathrm{OD}_{600}$ to 0.6 and infiltrated into 3-week-old Nicotiana benthamiana leaves. Analysis was carried out with a confocal microscope (Olympus FV1200, Tokyo, Japan). Conditions for imaging were set as 488-nm excitation, collecting bandwidth at 500 to $552 \mathrm{~nm}$ for GFP, 633-nm excitation, collecting bandwidth at 650 to 750 $\mathrm{nm}$ for chlorophyll autofluorescence.

\subsection{Quantitative Real-Time PCR Analysis}

Total RNA was extracted from different plant tissues by using the RNA RNeasy Plant Mini Kit (Qiagen, Duesseldorf, Germany). First-strand cDNA synthesis was performed using the PrimeScript ${ }^{\mathrm{TM}}$ RT reagent kit (Perfect Real Time; Takara, Dalian, China). qRT-PCR was performed to detect the transcript of PtoABCG36 in Arabidopsis and poplar by using the SYBR Green-based qPCR Master Mix (Promega, Madison, WI, USA). The gene-specific primers for qRT-PCR are listed in the supplementary Table S1. The poplar reference gene $U B Q$ (FJ438462) was used as an internal control to normalize the expression data. The PCR conditions and relative gene expression calculations were conducted as previously described [14]. Three biological replicates and three technical replicates were performed.

\subsection{Determination of Cadmium Content in Yeasts and Plants}

Cells of each line $\left(1 \times 10^{7}\right)$ were added to $30 \mathrm{~mL}$ of liquid SD-Ura medium containing $40 \mu \mathrm{M}$ $\mathrm{CdCl}_{2}$ and then cultured for different durations $(6,12,18$ or $24 \mathrm{~h})$ at $30^{\circ} \mathrm{C}$. The cells were then collected and washed twice with distilled water and digested with $\mathrm{HNO}_{3}$ and $\mathrm{H}_{2} \mathrm{O}_{2}(3: 1)$ at $140{ }^{\circ} \mathrm{C}$ for $10 \mathrm{~min}$, $200{ }^{\circ} \mathrm{C}$ for $20 \mathrm{~min}$ and $140{ }^{\circ} \mathrm{C}$ for $10 \mathrm{~min}$. The 2-week-old plants were immersed in half MS medium supplemented with $100 \mu \mathrm{M} \mathrm{CdCl}_{2}$ for $24 \mathrm{~h}$. Then, shoots and roots were digested with $\mathrm{HNO}_{3}$ and $\mathrm{H}_{2} \mathrm{O}_{2}$ (3:1) at $140{ }^{\circ} \mathrm{C}$ for $10 \mathrm{~min}, 200{ }^{\circ} \mathrm{C}$ for $20 \mathrm{~min}$ and $140{ }^{\circ} \mathrm{C}$ for $10 \mathrm{~min}$ [39]. All of samples were 
analyzed for total $\mathrm{Cd}$ detection by using Inductively Coupled Plasma Optical Emission Spectrometer (ICP-OES; ThermoFisher ICAP 6300, Waltham, MA, USA). All analyses were repeated three times.

\subsection{Net $\mathrm{Cd}^{2+}$ Efflux Measurements}

Fifteen-day-old seedlings were treated with $50 \mu \mathrm{M} \mathrm{CdCl}_{2}$ for $24 \mathrm{~h}$ and soaked in testing buffer (0.1 mM KCl, $0.1 \mathrm{mM} \mathrm{CaCl}_{2}, 0.05 \mathrm{mM} \mathrm{CdCl}_{2}, 0.3 \mathrm{mM}$ 2-( $\mathrm{N}$-morpholino) ethane sulfonic acid, pH 5.8) for $15 \mathrm{~min}$. Roots were immobilized on the bottom of a measuring dish in fresh testing buffer. The measuring site was $800 \mu \mathrm{m}$ from the root apex, and the net flux of $\mathrm{Cd}^{2+}$ was detected using a non-invasive micro-test technique (NMT; BIO-001A, Younger United States Science and Technology Corp, Beijing, China). The ion flux of $\mathrm{Cd}^{2+}$ was calculated according to Fick's law of diffusion, $J_{0}=-D$ $\times\left(d_{C} / d_{X}\right)$, where $J_{0}$ is the net ion flux (in $\mu \mathrm{mol} \cdot \mathrm{cm}^{-2}$ per second), $D$ is the self-diffusion coefficient for the ion (in $\left.\mathrm{cm}^{2} \cdot \mathrm{s}^{-1}\right), d_{C}$ is the difference in the ion concentrations between the two positions, and $d_{X}$ is the $10 \mu \mathrm{m}$ excursion over which the electrode moved in these experiments.

\subsection{Statistical Analysis}

The experimental data related to roots length, $\mathrm{Cd}$ content, $\mathrm{OD}_{600}$ of yeast, and quantitative RT-PCR were analyzed by the statistical software SPSS 9.0. One-way analysis of variance (ANOVA) with Duncan's multiple range tests was considered as significance test. Different letters represented significant differences $(p<0.05)$. Values represented means \pm standard deviation. Quantitative difference between two groups of data for comparison in each experiment was found to be statistically significant $\left({ }^{*} p<0.05 ; * * 00.01\right)$.

Supplementary Materials: Supplementary materials can be found at http://www.mdpi.com/1422-0067/20/13/ 3293/s1.

Author Contributions: Data curation, H.W., Y.L., X.W., S.X., L.S. and E.H.; Investigation, Y.L.; Methodology, B.W.; Project administration, J.L., Y.L., Z.P. and W.H.; Supervision, N.W. and B.W.; Validation, K.L.; Writing-original draft, H.W.; Writing-review \& editing, B.W. All authors reviewed the manuscript.

Funding: This work was supported by the National Natural Science Foundation of China (Grant No. 31571584 and 31370317), the Ministry of Science and Technology of China (Grant No. 2016YFD0100504), the Natural Science Foundation of Chongqing (Grant No. cstc2013jcyjA80016 and cstc2016shmszx20008), and Fundamental Research Funds for the Central Universities (XDJK2013B032), the National Undergraduate Training Programs for Innovation and entrepreneurship of China (Grant No. 201810635034).

Acknowledgments: We thank Ye Ning and Dexin Zhou for fruitful discussions and critical reading of the manuscript. We thank Ji-Ming Gong for kindly providing the yeast strains.

Conflicts of Interest: The authors declare no conflicts of interest.

\section{References}

1. Järup, L.; Åkesson, A. Current status of cadmium as an environmental health problem. Toxicol. Appl. Pharmacol. 2009, 238, 201-208. [CrossRef]

2. Kazantzis, G. Cadmium, osteoporosis and calcium metabolism. Biometals 2004, 17, 493-498. [CrossRef] [PubMed]

3. Goyer, R.A. Toxic and essential metal interactions. Annu. Rev. Nutr. 1997, 17, 37-50. [CrossRef] [PubMed]

4. Schützendübel, A.; Schwanz, P.; Teichmann, T.; Gross, K.; Langenfeld Heyser, R.; Godbold, D.L.; Polle, A. Cadmium-induced changes in antioxidative systems, hydrogen peroxide content, and differentiation in Scots pine roots. Plant Physiol. 2001, 127, 887-898. [CrossRef] [PubMed]

5. Hussain, D.; Haydon, M.J.; Wang, Y.; Wong, E.; Sherson, S.M.; Young, J.; Camakaris, J.; Harper, J.F.; Cobbett, C.S. P-type ATPase heavy metal transporters with roles in essential zinc homeostasis in Arabidopsis. Plant Cell 2004, 16, 1327-1339. [CrossRef]

6. Clemens, S. Molecular mechanisms of plant metal tolerance and homeostasis. Planta 2001, 212, 475-486. [CrossRef] [PubMed]

7. Williams, L.E.; Pittman, J.K.; Hall, J.L. Emerging mechanisms for heavy metal transport in plants. Biochim. Biophys. Acta. Biomembr. 2000, 1465, 104-126. [CrossRef] 
8. Do, T.H.T.; Martinoia, E.; Lee, Y. Functions of ABC transporters in plant growth and development. Curr. Opin. Plant Biol. 2018, 41, 32-38. [CrossRef] [PubMed]

9. Szczypka, M.S.; Wemmie, J.A.; Moye Rowley, W.S.; Thiele, D.J. A yeast metal resistance protein similar to human cystic fibrosis transmembrane conductance regulator (CFTR) and multidrug resistance-associated protein. J. Biol. Chem. 1994, 269, 22853-22857.

10. Song, W.Y.; Sohn, E.J.; Martinoia, E.; Lee, Y.J.; Yang, Y.Y.; Jasinski, M.; Forestier, C.; Hwang, I.; Lee, Y. Engineering tolerance and accumulation of lead and cadmium in transgenic plants. Nat. Biotechnol. 2003, 21, 914. [CrossRef]

11. Ortiz, D.F.; Ruscitti, T.; Mccue, K.F.; Ow, D.W. Transport of metal-binding peptides by HMT1, a fission yeast ABC-type vacuolar membrane protein. J. Biol. Chem. 1995, 270, 4721-4728. [CrossRef] [PubMed]

12. Kim, D.Y.; Bovet, L.; Kushnir, S.; Noh, E.W.; Martinoia, E.; Lee, Y. AtATM3 is involved in heavy metal resistance in Arabidopsis. Plant physiol. 2006, 140, 922-932. [CrossRef] [PubMed]

13. Park, J.; Song, W.Y.; Ko, D.; Eom, Y.; Hansen, T.H.; Schiller, M.; Lee, T.G.; Martinoia, E.; Lee, Y. The phytochelatin transporters AtABCC1 and AtABCC2 mediate tolerance to cadmium and mercury. Plant J. 2012, 69, 278-288. [CrossRef] [PubMed]

14. Song, W.Y.; Yamaki, T.; Yamaji, N.; Ko, D.; Jung, K.H.; Fujii Kashino, M.; An, G.; Martinoia, E.; Lee, Y.; Ma, J.F. A rice $\mathrm{ABC}$ transporter, OsABCC1, reduces arsenic accumulation in the grain. Proc. Natl. Acad. Sci. USA 2014, 111, 15699-15704. [CrossRef] [PubMed]

15. Sun, L.; Ma, Y.; Wang, H.; Huang, W.; Wang, X.; Han, L.; Sun, W.; Han, E.; Wang, B. Overexpression of PtABCC1 contributes to mercury tolerance and accumulation in Arabidopsis and poplar. Biochem. Biophys. Res. Commun. 2018, 497, 997-1002. [CrossRef] [PubMed]

16. Tommasini, R.; Vogt, E.; Fromenteau, M.; Hörtensteiner, S.; Matile, P.; Amrhein, N.; Martinoia, E. An ABC-transporter of Arabidopsis thaliana has both glutathione-conjugate and chlorophyll catabolite transport activity. Plant J. 1998, 13, 773-780. [CrossRef] [PubMed]

17. Gaillard, S.; Jacquet, H.; Vavasseur, A.; Leonhardt, N.; Forestier, C. AtMRP6/AtABCC6, an ATP-Binding Cassette transporter gene expressed during early steps of seedling development and up-regulated by cadmium in Arabidopsis thaliana. BMC Plant Biol. 2008, 8, 22. [CrossRef]

18. Kim, D.Y.; Bovet, L.; Maeshima, M.; Martinoia, E.; Lee, Y. The ABC transporter AtPDR8 is a cadmium extrusion pump conferring heavy metal resistance. Plant J. 2007, 50, 207-218. [CrossRef]

19. Migocka, M.; Papierniak, A.; Rajsz, A. Cucumber PDR8/ABCG36 and PDR12/ABCG40 plasma membrane proteins and their up-regulation under abiotic stresses. Biol. Plant. 2017, 61, 115-126. [CrossRef]

20. Oda, K.; Otani, M.; Uraguchi, S.; Akihiro, T.; Fujiwara, T. Rice ABCG43 Is Cd Inducible and Confers Cd Tolerance on Yeast. Bios. Biotechnol. Biochem. 2011, 75, 1211-1213. [CrossRef]

21. Melnikova, N.V.; Borkhert, E.V.; Snezhkina, A.V.; Kudryavtseva, A.V.; Dmitriev, A.A. Sex-Specific Response to Stress in Populus. Front. Plant Sci. 2017, 8, 1827. [CrossRef] [PubMed]

22. Shi, W.G.; Liu, W.; Yu, W.; Zhang, Y.; Ding, S.; Li, H.; Mrak, T.; Kraigher, H.; Luo, Z.B. Abscisic acid enhances lead translocation from the roots to the leaves and alleviates its toxicity in Populus $\times$ canescens. J. Hazard. Mater. 2019, 362, 275-285. [CrossRef] [PubMed]

23. Li, N.; Meng, H.; Xing, H.; Liang, L.; Zhao, X.; Luo, K.; Raines, C. Genome-wide analysis of MATE transporters and molecular characterization of aluminum resistance in Populus. J. Exp. Bot. 2017, 68, 5669-5683. [CrossRef] [PubMed]

24. Shim, D.; Kim, S.; Choi, Y.I.; Song, W.Y.; Park, J.; Youk, E.S.; Jeong, S.C.; Martinoia, E.; Noh, E.W.; Lee, Y. Transgenic poplar trees expressing yeast cadmium factor 1 exhibit the characteristics necessary for the phytoremediation of mine tailing soil. Chemosphere 2013, 90, 1478-1486. [CrossRef] [PubMed]

25. Schneider, E.; Hunke, S. ATP-binding-cassette (ABC) transport systems: Functional and structural aspects of the ATP-hydrolyzing subunits/domains. FEMS Microbiol. Rev. 1998, 22, 1-20. [CrossRef] [PubMed]

26. Hyde, S.C.; Emsley, P.; Hartshorn, M.J.; Mimmack, M.M.; Gileadi, U.; Pearce, S.R.; Gallagher, M.P.; Gill, D.R.; Hubbard, R.E.; Higgins, C.F. Structural model of ATP-binding proteing associated with cystic fibrosis, multidrug resistance and bacterial transport. Nature 1990, 346, 362-365. [CrossRef] [PubMed]

27. Kobae, Y.; Sekino, T.; Yoshioka, H.; Nakagawa, T.; Martinoia, E.; Maeshima, M. Loss of AtPDR8, a Plasma Membrane ABC Transporter of Arabidopsis thaliana, Causes Hypersensitive Cell Death Upon Pathogen Infection. Plant Cell Physiol. 2006, 47, 309-318. [CrossRef] [PubMed] 
28. Ji, H.; Peng, Y.; Meckes, N.; Allen, S.; Stewart, C.N.; Traw, M.B. ATP-Dependent Binding Cassette Transporter G Family Member 16 Increases Plant Tolerance to Abscisic Acid and Assists in Basal Resistance against Pseudomonas syringae DC3000. Plant Physiol. 2014, 166, 879-888. [CrossRef]

29. Khare, D.; Choi, H.; Huh, S.U.; Bassin, B.; Kim, J.; Martinoia, E.; Sohn, K.H.; Paek, K.H.; Lee, Y. Arabidopsis ABCG34 contributes to defense against necrotrophic pathogens by mediating the secretion of camalexin. Proc. Natl. Acad. Sci. USA 2017, 114, 5712-5720. [CrossRef]

30. Kuromori, T.; Sugimoto, E.; Shinozaki, K. Arabidopsis mutants of AtABCG22, an ABC transporter gene, increase water transpiration and drought susceptibility. Plant J. 2011, 67, 885-894. [CrossRef]

31. Moons, A. Osgstu 3 and osgtu4, encoding tau class glutathione S-transferases, are heavy metal- and hypoxic stress-induced and differentially salt stress-responsive in rice roots. FEBS Lett. 2003, 553, 427-432. [CrossRef]

32. Ogawa, I.; Nakanishi, H.; Mori, S.; Nishizawa, N.K. Time course analysis of gene regulation under cadmium stress in rice. Plant Soil. 2009, 325, 97-108. [CrossRef]

33. Songbiao, C.; Pattavipha, S.; Jianli, L.; Guo Liang, W. A versatile zero background T-vector system for gene cloning and functional genomics. Plant Physiol. 2009, 150, 1111-1121.

34. Rentsch, D.; Laloi, M.; Rouhara, I.; Schmelzer, E.; Delrot, S.; Frommer, W.B. NTR1 encodes a high affinity oligopeptide transporter in Arabidopsis. FEBS Lett. 1995, 370, 264-268. [CrossRef]

35. Peng, J.S.; Ding, G.; Meng, S.; Yi, H.Y.; Gong, J.M. Enhanced metal tolerance correlates with heterotypic variation in SpMTL, a metallothionein-like protein from the hyperaccumulator Sedum plumbizincicola. Plant Cell Environ. 2017, 40, 1368-1378. [CrossRef] [PubMed]

36. Gietz, R.D.; Schiestl, R.H. Frozen competent yeast cells that can be transformed with high efficiency using the LiAc/SS carrier DNA/PEG method. Nat. Protoc. 2007, 2, 1-4. [CrossRef] [PubMed]

37. Wemmie, J.A.; Szczypka, M.S.; Thiele, D.J.; Moye Rowley, W.S. Cadmium tolerance mediated by the yeast AP-1 protein requires the presence of an ATP-binding cassette transporter-encoding gene, YCF1. J. Biol. Chem. 1994, 269, 32592-32597. [PubMed]

38. Clough, S.J.; Bent, A.F. Floral dip: A simplified method for Agrobacterium-mediated transformation of Arabidopsis thaliana. Plant J. 1998, 16, 735-743. [CrossRef]

39. Brunetti, P.; Zanella, L.; De Paolis, A.; Di Litta, D.; Cecchetti, V.; Falasca, G.; Barbieri, M.; Altamura, M.M.; Costantino, P.; Cardarelli, M. Cadmium-inducible expression of the ABC-type transporter AtABCC3 increases phytochelatin-mediated cadmium tolerance in Arabidopsis. J. Exp. Bot. 2015, 66, 3815-3829. [CrossRef] 